\title{
Diffusion of the Digital Health Self-Tracking Movement in Canada: Results of a National Survey
}

Guy Paré ${ }^{1}$, PhD; Chad Leaver ${ }^{2}$, MSc, MBA; Claire Bourget ${ }^{3}$, MBA

${ }^{1}$ Research Chair in Digital Health, HEC Montreal, Montreal, QC, Canada

${ }^{2}$ Canada Health Infoway, Toronto, ON, Canada

${ }^{3}$ CEFRIO, Montreal, QC, Canada

\section{Corresponding Author:}

Guy Paré, PhD

Research Chair in Digital Health

HEC Montreal

3000 Cote-Sainte-Catherine Road

Montreal, QC,

Canada

Phone: 15143406812

Email: guy.pare@hec.ca

\section{Abstract}

Background: With the ever-increasing availability of mobile apps, consumer wearables, and smart medical devices, more and more individuals are self-tracking and managing their personal health data.

Objective: The aim of this study was to investigate the diffusion of the digital self-tracking movement in Canada. It provides a comprehensive, yet detailed account of this phenomenon. It examines the profile of digital self-trackers, traditional self-trackers, and nontrackers, further investigating the primary motivations for self-tracking and reasons for nontracking; barriers to adoption of connected care technologies; users' appreciation of their self-tracking devices, including what they perceive to be the main benefits; factors that influence people's intention to continue using connected care technologies in the future; and the reasons for usage discontinuance.

Methods: We conducted an online survey with a sample of 4109 Canadian adults, one of the largest ever. To ensure a representative sample, quota method was used (gender, age), following stratification by region. The maximum margin of error is estimated at $1.6 \%, 19$ times out of 20 .

Results: Our findings reveal that $66.20 \%$ (2720/4109) of our respondents regularly self-track one or more aspects of their health. About one in 4 respondents $(1014 / 4109,24.68 \%)$ currently owns a wearable or smart medical device, and 57.20\% (580/1014) use their devices on a regular basis for self-tracking purposes. Digital self-trackers are typically young or mature adults, healthy, employed, university educated, with an annual family income of over \$80,000 CAD. The most popular reported device is the fitness tracker or smartwatch that can capture a range of parameters. Currently, mobile apps and digital self-tracking devices are mainly used to monitor physical activity $(856 / 1669,51.13 \%)$, nutrition $(545 / 1669,32.65 \%)$, sleep patterns $(482 / 1669,28.88 \%)$ and, to a much lesser extent, cardiovascular and pulmonary biomarkers $(215 / 1669,12.88 \%)$, medication intake $(126 / 1669,7.55 \%)$, and glucose level $(79 / 1669,4.73 \%)$. Most users of connected care technologies $(481 / 580,83.0 \%)$ are highly satisfied and $88.2 \%$ (511/580) intend to continue using their apps and devices in the future. A majority said smart digital devices have allowed them to maintain or improve their health condition $(398 / 580,68.5 \%)$ and to be better informed about their health in general $(387 / 580$, $66.6 \%$ ). About $33.80 \%$ of our sample (1389/4109) is composed of people who do not monitor their health or well-being on a regular basis.

Conclusions: Our study shows an opportunity to advance the health of Canadians through connected care technologies. Our findings can be used to set baseline information for future research on the rise of digital health self-tracking and its impacts. Although the use of mobile apps, consumer wearables, and smart medical devices could potentially benefit the growing population of patients with chronic conditions, the question remains as to whether it will diffuse broadly beyond early adopters and across cost inequities.

(J Med Internet Res 2018;20(5):e177) doi: 10.2196/jmir.9388 


\section{KEYWORDS}

self-tracking; quantified-self; wearable devices; activity trackers; survey methodology

\section{Introduction}

In The patient will see you now, Eric Topol describes mobile phones as the Gutenberg of health care [1]. He argues that small mobile devices with wireless connectivity will prove to be the transformative catalyst for advancing toward the future of medicine. Although the mobile phone remains the device of choice for most individuals, technology manufacturers are creating a future of consumer wearables and smart medical devices that promise to help people live healthier lives [2]. Several such devices are currently available, including physical activity trackers that measure fitness-related metrics such as distance walked or ran; smart forks that vibrate when people eat too fast; smart toothbrushes with $3 \mathrm{D}$ motion sensors that monitor brushing performance; and smart clothes (eg, biometric shirts) that measure a person's breathing, pulse, calories, and sleep patterns. Recent estimates predict that 5.2 billion consumer smart devices are in use globally in 2017, setting the stage for an estimated 12.9 billion devices to be deployed by 2020 [3]. Other forecasts indicate that the consumer wearable device market value will reach US \$41 billion by 2020 from US \$2 billion in 2014 [4].

The need to attach personal numeric data to day-to-day activities such as eating, sleeping, and exercising is called the "quantified-self" movement [5]. Proponents of this movement believe that if they can measure an aspect of their life on a regular basis, they can find a way to improve it [6]. Computers can facilitate self-tracking because of advances in sensor technologies, ubiquity of access to information brought by the Internet, and improvements in user-friendly systems and interfaces [7]. Prior research shows that the measurement of one's daily activities with the assistance of mobile devices provides an advantage with respect to automatic and aggregated data compilation. People have limited memory and capacity to accurately and consistently track computational data about their behaviors such as counting the number of steps throughout the day [7-9]. Another advantage is that data from wearable sensors and smart medical devices can generate automated analytics over time, aggregating personally relevant feedback, which may, in turn, contribute to the sustainable use of digital devices [10,11].

Many experts say the rise of the Internet of Things will bring the next revolution in digital health [12]. Recent surveys on the adoption and impact of consumer digital health technologies reveal important insight about the current state and the trajectory of the purported potential. For instance, a survey of 2225 US adults reveals that the use of wearable self-tracking devices has doubled from 2014 (9\%) to 2016 (21\%) [13]. This study also indicates that millennials (aged 18-34 years) are the most prevalent users $(36 \%)$. Another US-based survey $(n=2025)$ on telemedicine, wearables, and postdischarge care found that $27 \%$ of adults own a self-tracking device and that $78 \%$ would want their doctor to have access to data from their wearables [14]. In Europe, a national survey of 1005 French citizens (aged 15+ years) reveals that $11 \%$ possess a health wearable or smart medical device, and $30 \%$ of nonusers have a firm intention to buy one in the next 12 months [15]. Finally, a 2016 online survey of more than 20,000 consumers (aged 15+ years) from 16 countries reported that $33 \%$ of respondents tracked their physical activity via a mobile app and a fitness band, clip, or smartwatch [16].

Although the abovementioned surveys set relevant baseline information, they do not provide a comprehensive and detailed account of the digital self-tracking movement. Specifically, no prior empirical research has attempted to investigate the sociodemographic and preference profile of digital self-trackers, traditional self-trackers, and nontrackers; the primary reasons for self-tracking and nontracking; the barriers to adoption of smart and connected health devices; users' perceived benefits of these devices; the factors that influence people's intention to continue using connected care technologies in the future; and the reasons for usage discontinuance that remain largely unknown. This study aims to fill this important gap and presents a timely and relevant integration of these issues, which may inform technology manufacturers, health care providers (HCPs), and policy makers' perceptions and future decisions in this area.

\section{Methods}

\section{Study Design and Sample}

In this section, we report the online survey that was conducted in according with the Checklist for Reporting Results of Internet E-Surveys checklist [17]. We first developed a comprehensive questionnaire instrument to administer with the general Canadian population in 2017. The instrument was based on a review of the extant literature on mobile health (mHealth) and digital self-tracking and was originally designed in French and back translated to English. The questionnaire was pretested during face-to-face interviews with 16 adults representative of the Canadian population in terms of age, gender, and language. Some minor adjustments were made to the questionnaire following this initial step.

The online survey was administered by AC Nielsen Company of Canada. The sample used for this research was the company's proprietary online panel, known as the Harris Panel. This panel is one of the largest, most representative, and best profiled panels in Canada. To begin survey administration, panel members were invited to participate in the study by email. Once participants clicked on the URL provided in the email letter, they were screened for the following eligibility criteria: (1) Canadian resident, (2) aged 18 years or older, and (3) spoke English or French. Those who were eligible read an informed consent form that emphasized the anonymity and confidentiality of respondents and advised that by completing the questionnaire, they are providing their consent to participate. All study procedures were approved by the HEC Montreal's research ethics committee. To ensure a representative sample, the quota method was used (gender, age), following stratification by Canadian geographic regions. 
Survey respondents were able to enter the survey at any point during the data collection period, that is, from January 11, 2017 to February 2, 2017. Respondents who partially completed the survey were able to exit the questionnaire and return at a later time to enter additional data. This could be done as many times as necessary. In accessing the online survey, respondents were assigned a unique identifier and passcode that allowed them access their data until the survey was finished. Participants were rewarded points for survey completion. Rewards for completing AC Nielsen surveys range in value from \$5 CAD to \$75 CAD. Standard options include gift cards and merchandise (eg, Amazon, iTunes, magazine subscriptions, Starbucks, Wal-Mart, and a variety of restaurant gift cards).

\section{Survey Items}

Gender, age, region, gross family income, education, occupation, and use of mobile phones and digital tablets were assessed by standard survey items administered in other international surveys [13-16]. Overall health status was obtained by asking participants to self-rate their own health on a scale from $1=$ poor or fair to 5=very good or excellent. This single-item measure has been used extensively worldwide and represents a valid and acceptable measure [18]. We also asked participants if they had one or several of the following chronic conditions: (1) diabetes, (2) high blood pressure, (3) obesity, (4) cardiovascular disease, (5) lung or respiratory airway disease, (6) cancer, (7) bone or muscular disease, (8) disease of nervous system, (9) mental disorder, (10) chronic infectious disease, and (11) addiction to tobacco or drugs.

Familiarity with connected care technologies was measured by asking "How familiar are you with consumer health wearables and smart medical devices?" using a 5-point Likert scale, where $1=$ not much at all and 5=extremely. We then asked, "Which of the following devices do you own?" using descriptive nonbrand terms for 13 specific devices commonly listed in the extant literature and available in Canada (see Results section). For each device they own, respondents were then asked how often they use it using a 7-point scale, where $1=$ once a month or less and $7=$ many times each day.

Motivations for using digital health self-tracking devices were measured with 10 items developed for this study using 5-point Likert scales, where $1=$ not at all and 5=very strongly. Items were derived from prior surveys on consumer digital health [12-16]. Examples of items include "know myself better," "give me daily encouragement toward reaching my personal goals," "better follow the treatment plan prescribed by my physician," and "break a bad habit related to my health." Data-sharing behaviors were assessed with a single item asking "Do you ever share with other people the data stored in your device or mobile app?" When answering “yes," respondents were then asked with whom (eg, family members, friends, family doctor, pharmacist, or personal trainer).

Respondents' appreciation of wearables and smart devices were captured with five variables. Measures for perceived usefulness ( 7 items) and ease of use (4 items) were adapted to the context of this study from Davis [19]. For their part, user satisfaction (3 items), confirmation of initial expectations ( 3 items), and intention to continue using wearables and smart devices (3 items) were adapted from Bhattacherjee [20] and Hong et al [21]. All five variables were assessed using 5-point Likert scales, where $1=$ strongly disagree and $5=$ strongly agree.

Finally, we asked respondents (when applicable) why they did not currently possess health wearables or smart devices. We developed a list of 10 reasons (see Results section), and respondents only checked those that applied to their personal situation. In a similar fashion, we developed a list of 11 items (see next section) that correspond to the reasons why consumers stopped using their wearables and smart devices at some point. Both lists of items were derived from prior surveys on consumer digital health [12-16]. The complete online survey instrument is provided in Multimedia Appendix 1.

\section{Data Analyses}

In line with our research objectives, we analyzed the entire sample as well as specific subgroups. General trends regarding ownership and use of connected care technologies are analyzed with descriptive statistics (mean, SD, percentage), comparisons between self-trackers and nontrackers are analyzed with multinomial logistic regression tests, and users' appreciation of digital self-tracking devices is analyzed using Pearson correlation tests and partial least squares (PLS) multiple regression analyses. Analyses are performed using the SPSS (IBM Corp) version 23 software and the SmartPLS (SmartPLS $\mathrm{GmbH}$ ) version 3.2.7 software.

\section{Results}

\section{Profile of the Sample}

Our sample is composed of 4109 adults. The maximum margin of error is estimated at 1.6\%, 19 times out of 20. Table 1 presents the profile of the sample according to usual sociodemographic variables, in comparison with the total Canadian population. The sample was composed of 2118 men, representing $51.55 \%$. In terms of age, $27.84 \%$ of all respondents (1144/4109) were millennials (18-34 years), whereas $35.17 \%$ (1445/4109) consisted of baby boomers (55+ years). As expected, the majority of respondents were from the two largest Canadian provinces, namely, Ontario (1575/4109, 38.33\%) and Quebec (986/4109, 24.00\%). About 1 out of 5 respondents had a gross family annual income of less than $\$ 40,000 \mathrm{CAD}$, whereas $35.58 \%(1462 / 4109)$ had annual family incomes superior to $\$ 80,000$ CAD. Our survey participants were more educated than the Canadian population according to data from the 2016 national census. Almost half of the respondents had a university degree compared with $28.70 \%$ for the whole population, 6 out of 10 respondents were workers (2386/4109), less than $4 \%(3.68 \%, 151 / 4109)$ were students, and slightly over $23 \%(22.8 \%, 937 / 4109)$ were retired. Overall, our data indicate that, except for education, the sociodemographic profile of our respondents is representative of the adult population in Canada.

In terms of health status, less than $10 \%$ of all respondents $(9.78 \%, 402 / 4109)$ perceived themselves to be in poor or fair condition, whereas $50.38 \%$ (2070/4109) said they were in good health, and $39.84 \%(1637 / 4109)$ perceived themselves in very good or excellent health. 
Table 1. Profile of the sample and comparisons with the Canadian population.

\begin{tabular}{|c|c|c|}
\hline Characteristics & Sample $(\mathrm{N}=4109), \mathrm{n}(\%)$ & Canadian population $(\mathrm{N}=35,151,730), \mathrm{n}(\%)$ \\
\hline \multicolumn{3}{|l|}{ Gender } \\
\hline Male & $2118(51.55)$ & $17,264,200(49.11)^{\mathrm{a}}$ \\
\hline Female & $1991(49.45)$ & $17,887,530(50.89)^{\mathrm{a}}$ \\
\hline \multicolumn{3}{|l|}{ Age (years) } \\
\hline $18-34$ & $1144(27.84)$ & $6,858,075(25.27)^{\mathrm{a}}$ \\
\hline $35-54$ & $1520(36.99)$ & $9,581,540(27.28)^{\mathrm{a}}$ \\
\hline $55+$ & $1445(35.17)$ & $10,846,380(30.86)^{\mathrm{a}}$ \\
\hline \multicolumn{3}{|l|}{ Region } \\
\hline Atlantic provinces & $293(7.13)$ & $2,385,779(6.58)^{\mathrm{a}}$ \\
\hline Quebec & $986(24.00)$ & $8,321,888(22.95)^{\mathrm{a}}$ \\
\hline Ontario & $1575(38.33)$ & $13,976,320(38.54)^{\mathrm{a}}$ \\
\hline Manitoba and Saskatchewan & $266(6.47)$ & $2,466,703(6.80)^{\mathrm{a}}$ \\
\hline Alberta & $437(10.64)$ & $4,236,376(11.68)^{\mathrm{a}}$ \\
\hline British Columbia and Northwest Territories & $552(13.43)$ & $4,802,275(13.24)^{\mathrm{a}}$ \\
\hline \multicolumn{3}{|l|}{ Gross family income $^{b}(\$ C A D)$} \\
\hline$<\$ 20 \mathrm{k}$ & $268(6.52)$ & $8,558,000(29.88)^{\mathrm{a}}$ \\
\hline$\geq \$ 20 \mathrm{k}$ and $<\$ 40 \mathrm{k}$ & $583(14.19)$ & $7,014,015(24.48)^{\mathrm{a}}$ \\
\hline$\geq \$ 40 \mathrm{k}$ and $<\$ 60 \mathrm{k}$ & $614(14.94)$ & $5,006,820(17.48)^{\mathrm{a}}$ \\
\hline$\geq \$ 60 \mathrm{k}$ and $<\$ 80 \mathrm{k}$ & $561(13.65)$ & $2,926,920(10.22)^{\mathrm{a}}$ \\
\hline$\geq \$ 80 \mathrm{k}$ and $<\$ 100 \mathrm{k}$ & $498(12.12)$ & $1,716,175(5.99)^{\mathrm{a}}$ \\
\hline$\geq \$ 100 \mathrm{k}$ & 964 (23.46) & $2,266,600(7.91)^{\mathrm{a}}$ \\
\hline \multicolumn{3}{|l|}{ Education level } \\
\hline High school or college & $2051(51.13)$ & $18,730,750(65.39)^{\mathrm{a}}$ \\
\hline Undergraduate & $1300(32.41)$ & $6,659,615(23.25)^{\mathrm{a}}$ \\
\hline Graduate & $660(16.45)$ & $1,562,555(5.45)^{\mathrm{a}}$ \\
\hline \multicolumn{3}{|l|}{ Occupation } \\
\hline Workers & $2386(58.86)$ & $17,230,040(60.15)^{\mathrm{a}}$ \\
\hline Students & $151(3.72)$ & $19,992,283(6.99)^{\mathrm{a}}$ \\
\hline Retirees & $937(23.11)$ & $4,912,278(17.15)^{\mathrm{a}}$ \\
\hline Other & $580(14.31)$ & $4,284,996(15.96)^{\mathrm{a}}$ \\
\hline \multicolumn{3}{|l|}{ Perceived health status } \\
\hline Bad or average & $402(9.78)$ & $3,443,000(12.00)^{\mathrm{c}}$ \\
\hline Good & $2070(50.38)$ & $9,561,713(29.00)$ \\
\hline Very good or excellent & $1637(39.84)$ & $18,714,100(59.00)^{\mathrm{c}}$ \\
\hline \multicolumn{3}{|l|}{ Chronic diseases } \\
\hline Yes & $1281(31.89)$ & $12,053,150(38.00)^{\mathrm{c}}$ \\
\hline No & $2735(68.11)$ & $19,665,665(62.00)^{\mathrm{c}}$ \\
\hline
\end{tabular}




\begin{tabular}{lll}
\hline Characteristics & Sample $(\mathrm{N}=4109), \mathrm{n}(\%)$ & Canadian population $(\mathrm{N}=35,151,730), \mathrm{n}(\%)$ \\
\hline Language used to complete the questionnaire & & - \\
$\quad$ English & $3644(88.68)$ & - \\
French & $465(11.32)$ & - \\
\hline
\end{tabular}

${ }^{\text {a }}$ Statistics Canada Census 2016.

${ }^{\text {b }}$ The median total income in Canada was \$80,940 CAD in 2015 according to the Statistics Canada Census 2016.

${ }^{\mathrm{c}}$ Health Canada Survey 2014.

Aligned to general population estimates for Canada, the majority of respondents $(2735 / 4109,68.11 \%)$ reported no chronic conditions. The most common self-reported chronic conditions were hypertension, diabetes, and obesity.

\section{Use of Mobile Devices}

Our findings indicate that $78.10 \%$ of all respondents (3209/4109) owned a mobile phone (eg, Apple iPhone, Samsung Galaxy, Google Nexus, Microsoft Lumia, or Sony Xperia) and used it to download mobile apps, among other things. Our results also show that $56.88 \%$ of our respondents (2337/4109) owned a digital tablet (eg, Apple iPad, Samsung Galaxy Tab, Google Nexus Tablet, or Sony Xperia Tablet). These statistics are similar to those reported by the Canadian Radio-television and Telecommunications Commission, which found that in 2016, $73 \%$ of Canadian adults owned a mobile phone, and $52 \%$ owned a tablet [22]. Overall, $86.01 \%$ of our respondents (3534/4109) used either a mobile phone or a tablet, whereas $48.97 \%$ (2012/4109) reported owning both devices. As expected, age is negatively associated with use of a mobile device $\left(\chi_{4}^{2}=389.3\right.$; $P<.001)$; $56.24 \%$ of millennials (18-34 years) using both devices compared with $37.11 \%$ among baby boomers (55+ years).

\section{Self-Tracking Behaviors}

We defined three self-tracking profiles for the study. Respondents that regularly track one or more aspect of their health or well-being using connected care technologies, that is, mHealth apps, consumer wearables (eg, fitness trackers), and smart medical devices (eg, blood pressure monitors) were defined as "digital self-trackers." Respondents who regularly monitor one or more aspect of their health using manual tools (other than a mobile app or smart device) such as simply recording the information in writing (on paper, or in a journal or notebook) or by remembering the information were defined as "traditional self-trackers." The remaining respondents reporting that they do not regularly monitor any aspect of their personal health or well-being were defined as "nontrackers."

Table 2 reveals that whether through digital or traditional means, the prevalence of self-trackers in Canada is about two-thirds (2720/4109, 66.20\%), a number that is similar to recent estimates from the United States [23]. Our sample is composed of two distinct groups of self-trackers. The first, digital self-trackers comprise $40.61 \%$ (1669/4109) of our sample and $61.36 \%$ of all self-trackers (1669/2720). This group comprises as many men as women who are, for the most part, active members of the workforce. A majority of digital self-trackers are young or mature adults (18-34 years), highly-educated, and wealthy individuals (average gross family income $\$ 80,000$
CAD), and people who perceive themselves to be in good or very good health. More than 7 out of 10 respondents in this group (1172/1669) self-report having no chronic diseases.

The second group, traditional self-trackers represents $25.58 \%$ $(1051 / 1669)$ of our sample and $38.64 \%$ of all self-trackers (1051/2720). Unlike digital self-trackers, this group comprises slightly more women than men. The majority of traditional trackers are aged 55 years and older, retired, with a gross family income substantially less than digital trackers. Importantly, individuals in this group are more likely to be living with one or several chronic diseases than digital self-trackers $(47.07 \%$ vs $28.36 \%$, respectively).

The third group, nontrackers, represents $33.80 \%$ of our sample (1389/4109). Like traditional trackers, this group comprises slightly less men than women. However, nontrackers are found in all age groups. They are less educated and have lower gross family income on average than the other two groups. One in four nontrackers reported having one or several chronic conditions. The most common reasons given by these respondents for not tracking any aspect of their health were as follows: "the information provided by my physician is sufficient" (335/1389, 24.12\%), "no need because I am in excellent health condition" (338/1389, 24.33\%), "I am simply not interested" $(329 / 1389,23.69 \%)$, and "I am not disciplined enough" (261/1389, 18.79\%). Four out of five nontrackers $(1095 / 1389,78.83 \%)$ possess a mobile phone or a tablet.

A multinomial logistic regression including all sociodemographic and health status variables was performed to calculate odds ratios describing the odds of tracking one's own health using traditional or digital devices compared with the odds of nontracking (reference category). The traditional 0.05 criterion of statistical significance was employed for all tests. Addition of the predictors to a model that contained only the intercept significantly improved the fit between model and data; $\chi_{36}^{2}(\mathrm{~N}=4109)=548.70$, Nagelkerke $R^{2}=0.32, P<.001$. As indicated in Table 3, our analyses determined no statistically significant differences between groups in terms of gender, region, occupation, and perceived health condition. However, significant differences were observed in terms of age, gross annual income, education level, and chronic condition(s). For instance, millennials (18-34 years) and people in the age range of 35 to 54 years were 3.7 and 1.5 times more likely to be in the digital self-tracking group than baby boomers (55+ years). As another example, compared with people living with no chronic condition, chronic patients were 0.4 times less likely to be in the traditional self-tracking group and 0.6 times less likely to be in the digital self-tracking group. 
Table 2. Profile of self-trackers and nontrackers $(\mathrm{N}=4109)$.

\begin{tabular}{|c|c|c|c|}
\hline Characteristics & Nontrackers (N=1389), n (\%) & Traditional self-trackers $(\mathrm{N}=1051), \mathrm{n}(\%)$ & Digital self-trackers (N=1669), n (\%) \\
\hline \multicolumn{4}{|l|}{ Gender } \\
\hline Male & $721(51.91)$ & $566(53.85)$ & $831(49.79)$ \\
\hline Female & $668(48.09)$ & $485(46.15)$ & $838(50.21)$ \\
\hline \multicolumn{4}{|l|}{ Age in years } \\
\hline $18-34$ & $314(22.61)$ & $147(13.98)$ & $684(40.98)$ \\
\hline $35-54$ & $539(38.80)$ & $347(33.02)$ & $633(37.93)$ \\
\hline $55+$ & $536(38.59)$ & $557(53.00)$ & $352(21.09)$ \\
\hline \multicolumn{4}{|l|}{ Region } \\
\hline Atlantic provinces & $106(7.63)$ & $78(7.42)$ & $109(6.53)$ \\
\hline Quebec & $368(26.49)$ & $253(24.07)$ & $365(21.87)$ \\
\hline Ontario & $513(36.93)$ & $414(39.39)$ & $648(38.83)$ \\
\hline Manitoba and Saskatchewan & $94(6.77)$ & $65(6.18)$ & $107(6.41)$ \\
\hline Alberta & $124(8.93)$ & $103(9.80)$ & $211(12.64)$ \\
\hline British Columbia and Terrace & $184(13.25)$ & $138(13.13)$ & $229(13.72)$ \\
\hline \multicolumn{4}{|l|}{ Gross family income (\$ CAD) } \\
\hline$<\$ 40 \mathrm{k}$ & $335(29.13)$ & $244(27.23)$ & $272(19.86)$ \\
\hline$\geq \$ 40 \mathrm{k}$ and $<\$ 60 \mathrm{k}$ & $244(21.22)$ & $171(19.08)$ & $200(13.87)$ \\
\hline$\geq \$ 60 \mathrm{k}$ and $<\$ 80 \mathrm{k}$ & $190(16.52)$ & $154(17.19)$ & $216(14.98)$ \\
\hline$\geq \$ 80 \mathrm{k}$ and $<\$ 100 \mathrm{k}$ & $145(12.61)$ & $109(12.16)$ & $244(16.92)$ \\
\hline$\geq \$ 100 \mathrm{k}$ and $<\$ 200 \mathrm{k}$ & $195(16.96)$ & $192(21.43)$ & $428(29.68)$ \\
\hline$\geq \$ 200 \mathrm{k}$ & $41(3.56)$ & $26(2.90)$ & $82(5.69)$ \\
\hline \multicolumn{4}{|l|}{ Education level } \\
\hline High school or college & $805(59.59)$ & $529(51.30)$ & $717(44.04)$ \\
\hline Undergraduate & $376(27.83)$ & $330(32.01)$ & $593(36.43)$ \\
\hline Graduate & $170(12.58)$ & $172(16.68)$ & $318(19.53)$ \\
\hline \multicolumn{4}{|l|}{ Occupation } \\
\hline Workers & $752(54.85)$ & $476(45.81)$ & 1158 (70.44) \\
\hline Students & $53(3.87)$ & $23(2.21)$ & $75(4.56)$ \\
\hline Retirees & $347(25.31)$ & $383(36.86)$ & $207(12.59)$ \\
\hline Other & $219(15.97)$ & $157(15.11)$ & $204(12.41)$ \\
\hline \multicolumn{4}{|l|}{ Perceived health condition } \\
\hline Bad or average & $118(8.50)$ & $127(12.08)$ & $157(9.41)$ \\
\hline Good & $712(51.26)$ & $524(49.86)$ & $833(49.91)$ \\
\hline Very good or excellent & $559(40.24)$ & $400(38.06)$ & $679(40.68)$ \\
\hline \multicolumn{4}{|l|}{ Chronic diseases } \\
\hline No & $1021(75.29)$ & $542(52.93)$ & $1172(71.64)$ \\
\hline Yes & $335(24.71)$ & $482(47.07)$ & $464(28.36)$ \\
\hline
\end{tabular}


Table 3. Multinomial logistic regression model predicting traditional tracking and e-tracking by patient characteristics. Reference category=nontrackers $(\mathrm{N}=1389)$.

\begin{tabular}{|c|c|c|c|c|}
\hline \multirow[t]{2}{*}{ Characteristics } & \multicolumn{2}{|c|}{ Traditional self-trackers $(\mathrm{N}=1051)$} & \multicolumn{2}{|c|}{ Digital self-trackers $(\mathrm{N}=1669)$} \\
\hline & Odds ratio $(95 \% \mathrm{CI})$ & Significance & Odds ratio $(95 \% \mathrm{CI})$ & Significance \\
\hline Intercept & - & $<.001$ & - & $<.001$ \\
\hline \multicolumn{5}{|l|}{ Gender } \\
\hline Female & $0.932(0.765-1.134)$ & .48 & $1.170(0.981-1.394)$ & .08 \\
\hline \multicolumn{5}{|l|}{ Age (years) } \\
\hline $18-34$ & $0.612(0.434-0.863)$ & .005 & $3.732(2.785-5.002)$ & $<.001$ \\
\hline $35-54$ & $0.728(0.555-0.954)$ & .02 & $1.552(1.193-2.018)$ & $<.001$ \\
\hline \multicolumn{5}{|l|}{ Region } \\
\hline Atlantic provinces & $1.055(0.682-1.633)$ & .81 & $0.921(0.619-1.370)$ & .69 \\
\hline Quebec & $1.022(0.739-1.414)$ & .90 & $0.858(0.641-1.147)$ & .30 \\
\hline Ontario & $1.038(0.764-1.410)$ & .81 & $0.963(0.733-1.263)$ & .78 \\
\hline Manitoba-Saskatchewan & $0.701(0.434-1.134)$ & .15 & $0.859(0.573-1.287)$ & .46 \\
\hline Alberta & $1.364(0.900-2.067)$ & .15 & $1.335(0.927-1.922)$ & .12 \\
\hline \multicolumn{5}{|l|}{ Gross family income (\$ CAD) } \\
\hline$\leq \$ 60 \mathrm{~K}$ & $0.750(0.552-1.019)$ & .07 & $0.429(0.326-0.566)$ & $<.001$ \\
\hline$>\$ 60 \mathrm{~K}$ and $\leq \$ 100 \mathrm{~K}$ & $0.853(0.673-1.081)$ & .19 & $0.550(0.447-0.675)$ & $<.001$ \\
\hline \multicolumn{5}{|l|}{ Education level } \\
\hline High school or college & $0.639(0.477-0.855)$ & .003 & $0.623(0.480-0.808)$ & $<.001$ \\
\hline Undergraduate & $0.797(0.590-1.077)$ & .14 & $0.832(0.637-1.086)$ & .18 \\
\hline \multicolumn{5}{|l|}{ Occupation } \\
\hline Workers & $0.808(0.608-1.075)$ & .14 & $1.292(0.956-1.746)$ & .01 \\
\hline Students & $0.900(0.442-1.834)$ & .77 & $0.680(0.376-1.229)$ & .20 \\
\hline Others & $0.704(0.483-1.027)$ & .07 & $0.877(0.603-1.275)$ & .49 \\
\hline \multicolumn{5}{|l|}{ Perceived health condition } \\
\hline Very poor or poor & $0.972(0.669-1.414)$ & .88 & $1.108(0.789-1.557)$ & .55 \\
\hline Fair or good & $0.923(0.749-1.137)$ & .45 & $1.007(0.837-1.212)$ & .94 \\
\hline \multicolumn{5}{|l|}{ Chronic disease(s) } \\
\hline One or several chronic disease(s) & $0.403(0.322-0.503)$ & $<.001$ & $0.548(0.443-0.677)$ & $<.001$ \\
\hline
\end{tabular}

\section{Motivations for Using Digital Self-Tracking Devices}

The use of digital self-tracking devices and mobile apps is mainly the result of motivations tied to sustaining individual well-being rather than monitoring or mediating medical problems or illnesses. More precisely, $57.94 \%$ of our respondents (967/1669) said they use connected care technologies mainly to know more about their condition and monitor changes in parameters that they consider important for their health. Another common motivation was associated with the day-to-day encouragement that digital health self-tracking technologies provide as people strive to meet their personal goals $(883 / 1669,52.91 \%)$. Importantly, $42.06 \%$ (702/1669) said they use digital self-tracking tools to monitor their progress in fitness or athletic training. For their part, motivations such as "follow the treatment plan prescribed by my physician" (447/1669, 26.78\%), "improve communication with my physician" (400/1669, 23.97\%), and "reduce the number of medical visits" (381/1669, 22.83\%) were not the primary drivers of use. Quite conversely, traditional self-trackers tend to monitor specific clinical parameters related to chronic conditions such as weight, heart rate, glucose level, and medication intake (see Table 4). 
Table 4. Health aspects monitored by digital and traditional self-trackers.

\begin{tabular}{lll}
\hline Dimension and health aspects & Digital self-trackers (N=1669), $\mathrm{n}(\%)$ & Traditional self-trackers (N=1051), $\mathrm{n}(\%)$ \\
\hline Well-being & & $441(41.96)$ \\
$\quad$ Physical activity & $856(51.13)$ & $392(37.30)$ \\
Nutrition and eating habits & $545(32.65)$ & $320(30.45)$ \\
Sleep patterns & $482(28.88)$ & $59(5.61)$ \\
Performance in sports & $256(15.34)$ & \\
Medical & & $585(55.66)$ \\
Weight-related data & $483(28.94)$ & $300(28.54)$ \\
Cardiovascular and respiratory health (eg, heart rate) & $215(12.88)$ & $339(32.25)$ \\
Medication intake & $126(7.55)$ & $247(23.50)$ \\
Glucose level & $79(4.73)$ & \\
\hline
\end{tabular}

\section{Adoption and Use of Wearable Connected Care Technologies}

At the time of our survey, $74 \%$ of respondents (or $86 \%$ of those with a mobile phone or tablet) had already heard of consumer health wearables and smart medical devices. However, the level of familiarity with these remains relatively low, as only $16 \%$ of respondents who had already heard of such devices also reported being "very or extremely" familiar with them. We found that the level of familiarity with these tools is negatively correlated with age $(r=-.21 ; P<.001)$ and positively correlated with family income $(r=.14 ; P<.001)$. Indeed, millennials $\left(\chi_{4}^{2}=50.0 ; P<.001\right)$ and people with annual family income over $\$ 80,000 \mathrm{CAD}\left(\chi_{4}^{2}=28.2 ; P=.03\right)$ were more likely to be familiar with digital self-tracking devices than the other groups.

More importantly, our findings indicate that 1014 out of 1669 digital self-trackers $(60.75 \%)$ own one or several wearables or smart medical devices, representing $24.68 \%$ of the entire sample. This ratio is similar to recent statistics from the United States. Indeed, according to two 2016 market reports, between $21 \%$ and $27 \%$ of American adults owned at least one such device $[13,14]$. Among our survey respondents, 70.02\% (710/1014) said they had one connected wearable device, $20.71 \%$ (210/1014) had two, and 9.07\% (92/1014) had three or more. On average, Canadian adults were using 1.5 consumer health wearable or smart medical device in early 2017. As these products are relatively new on the market, and our field administration shortly followed the 2016 holiday season, it is not surprising to observe that a majority of owners $(549 / 1014$, $54.14 \%$ ) had been using their devices for less than a year at the time of the survey.

Although $61.11 \%$ of digital self-trackers (1020/1669) said they owned one or several wearable connected devices, $34.75 \%$ (580/1669) actually use them to self-track one or several aspects of their health. A multinomial logistic regression was performed to model the relationship between the predictors and membership in the two groups (nonusers and users of smart wearables). Addition of the predictors to a model that contained only the intercept significantly improved the fit between model and data; $\chi_{18}^{2}(\mathrm{~N}=4109)=154.82$, Nagelkerke $R^{2}=0.23, P<.05$. As shown in Table 5, our analyses determined no statistically significant differences between users and nonusers of smart wearables in terms of gender, region, occupation, and education level. However, significant differences were observed in terms of age, gross annual income, perceived health status, and chronic condition(s). For one thing, millennials and people in the age range of 35 to 54 years were 2.2 and 1.6 times more likely to use digital devices to self-track their health than baby boomers (55+ years). For their part, people with annual family income inferior to $\$ 60,000 \mathrm{CAD}$ were 0.38 times less likely to use smart digital devices than those with annual incomes of $\$ 100,000$ CAD or more. Finally, our findings indicate that it is people who perceive themselves to be in very good or excellent health condition and those with no chronic condition who are current users of digital self-tracking devices.

In terms of usage, the most popular device is by far the bracelet or smartwatch, which is owned by $87.2 \%$ of those who own at least one such device (see Table 6). The main advantage often associated with wrist-wearable trackers is that they can monitor a range of health parameters and align with the common practice of wearing a watch. The bathroom scale and pedometer were the next most common connected devices used by Canadians.

Respondents were also asked how often they use connected self-tracking devices. Answers to this question varied across devices and according to the users' specific needs. For instance, $77.5 \%$ of those who have a bracelet or a smartwatch (392/506) use it several times per day. For its part, the bathroom scale is generally used once a day $(38 / 119,31.9 \%)$ or several times per week $(41 / 119,34.5 \%)$, whereas a minority $(13 / 119,10.9 \%)$ use it only a few times per month. As a final example, the blood pressure monitor is used once a month $(12 / 47,25 \%)$, once a day $(11 / 47,24 \%)$, or a few times per day $(8 / 47,16 \%)$ depending on the individual's condition and needs. 
Table 5. Multinomial logistic regression model predicting usage of health wearables and smart medical devices by patient characteristics. Reference category=nonusers $(\mathrm{N}=3529)$.

\begin{tabular}{|c|c|c|}
\hline \multirow[t]{2}{*}{ Characteristics } & \multicolumn{2}{|c|}{ Users of health wearables and smart medical devices $(\mathrm{N}=580)$} \\
\hline & Odds ratio $(95 \% \mathrm{CI})$ & Significance \\
\hline Intercept & - & $<.001$ \\
\hline \multicolumn{3}{|l|}{ Gender } \\
\hline Female & $1.041(0.846-1.282)$ & .70 \\
\hline \multicolumn{3}{|l|}{ Age (years) } \\
\hline $18-34$ & $2.234(1.577-3.167)$ & $<.001$ \\
\hline $35-54$ & $1.566(1.128-2.174)$ & .007 \\
\hline \multicolumn{3}{|l|}{ Region } \\
\hline Atlantic provinces & $0.962(0.592-1.563)$ & .88 \\
\hline Quebec & $0.752(0.522-1.083)$ & .13 \\
\hline Ontario & $1.120(0.811-1.546)$ & .49 \\
\hline Manitoba-Saskatchewan & $0.993(0.605-1.629)$ & .98 \\
\hline Alberta & $1.242(0.834-1.850)$ & .29 \\
\hline \multicolumn{3}{|l|}{ Gross family income (\$ CAD) } \\
\hline$\leq 60 \mathrm{~K}$ & $0.381(0.262-0.554)$ & $<.001$ \\
\hline$>60 \mathrm{~K}$ and $\leq 100 \mathrm{~K}$ & $0.638(0.511-0.797)$ & $<.001$ \\
\hline \multicolumn{3}{|l|}{ Education level } \\
\hline High school or college & $0.861(0.644-1.152)$ & .31 \\
\hline Undergraduate & $1.071(0.809-1.419)$ & .63 \\
\hline \multicolumn{3}{|l|}{ Occupation } \\
\hline Workers & $1.255(0.859-1.833)$ & .24 \\
\hline Students & $0.377(0.146-0.975)$ & .04 \\
\hline Others & $0.780(0.471-1.292)$ & .34 \\
\hline \multicolumn{3}{|l|}{ Perceived health status } \\
\hline Very poor or poor & $0.428(0.267-0.685)$ & $<.001$ \\
\hline Fair or good & $0.689(0.556-0.854)$ & $<.001$ \\
\hline \multicolumn{3}{|l|}{ Chronic disease(s) } \\
\hline One or more chronic condition(s) & $0.784(0.615-0.998)$ & .049 \\
\hline
\end{tabular}

\section{Data Sharing With Health Care Providers}

This study indicates that there are relatively few people who regularly share the data captured with their digital self-tracking devices. In fact, only $34.87 \%$ of users (582/1669) reported that they share their personal health data. When they do so, it is primarily with family members $(352 / 582,60.5 \%)$, friends (294/582, 50.5\%), and to a much lesser extent, an HCP such as a family doctor $(195 / 582,33.5 \%)$ or a pharmacist $(50 / 582$, $8.6 \%$ ). Although no direct comparisons could be made with other surveys, empirical evidence in the United States shows that $78 \%$ of adults who use health wearables would like their doctor to have access to their personal data [14]. Another recent survey conducted in Canada reveals that $67 \%$ of users of mobile apps would share their data if their doctor requested it [24].

\section{Users' Appreciation of Connected Care Technologies}

As shown in Tables 7 and 8, users of consumer wearables and connected devices claimed to be very satisfied (mean $=4.1$ on a 5-point Likert scale), perceived their devices to be user-friendly (mean=4.2), and had a firm intention of continuing to use them in the future (mean=4.3). Overall, respondents perceive these devices as highly useful. About 7 out of 10 users (398/580) said that they have maintained or improved their health status by using digital self-tracking connected devices. Importantly, a majority of users report they are more informed or more knowledgeable about their health condition. Close to 6 out of 10 users (435/580) said they feel more confident taking care of their health or more autonomous in the management of their condition. On the other hand, feeling less anxious about one's own health and having more informed discussions with a doctor were not perceived as major benefits digital self-trackers in our study. 
Table 6. Types of consumer wearables and smart medical devices among Canadian adults who use at least one such device (N=580).

\begin{tabular}{|c|c|}
\hline Types of wearables & $\mathrm{n}(\%)$ \\
\hline Bracelet, wristband or smartwatch & $506(87.2)$ \\
\hline Bathroom scale & $119(20.5)$ \\
\hline Pedometer & $76(13.1)$ \\
\hline Blood pressure monitor & $47(8.1)$ \\
\hline Intelligent toothbrush & $38(6.6)$ \\
\hline Pulse oximeter or spirometer (respiratory functions) & $35(6.0)$ \\
\hline Thermometer & $33(5.7)$ \\
\hline Glucose monitor & $25(4.3)$ \\
\hline Intelligent clothes (eg, pants, shirts, and socks) & $20(3.4)$ \\
\hline Spirometer & $16(2.8)$ \\
\hline Intelligent pill dispenser & $14(2.4)$ \\
\hline Intelligent fork & $11(1.9)$ \\
\hline
\end{tabular}

To further investigate users' appreciation of digital self-tracking devices, we tested a research model derived from the works of Bhattacherjee [20] and Hong et al [21], as well as expectation-confirmation theory [25]. To our knowledge, no prior research has investigated the factors influencing the continued usage of these devices. As shown in Figure 1, our model suggests that an individual's intention to continue using health wearables and smart devices is mainly influenced by his or her level of satisfaction. In turn, user satisfaction is influenced by the extent to which initial expectations toward these devices are confirmed, as well as by two factors from the Technology Acceptance Model (TAM) proposed by Davis [19], namely, ease of use and perceived usefulness. Following Hong et al [21], our model also proposes direct links between the TAM constructs and the dependent variable.

The reliability of the measures included in the model was determined with Cronbach alpha. Findings in Table 6 indicate that all the measures, without exception, surpass the 0.70 threshold of statistical significance [26]. This table also demonstrates the validity of the variables included in our research model. In particular, we see that the square root of the variance shared by each variable and its respective items is greater than the intercorrelations between the variables.

PLS regression analyses were performed to test the links in the model. Our findings in Figure 1 supported all relationships, and the model explains $64 \%$ of the variance in the dependent variable. Our results indicate that expectations confirmation is strongly related to TAM factors and user satisfaction. This result shows the importance of properly managing consumers' initial expectations to ensure greater adherence and continued usage of health wearables and smart medical devices. Future research on this topic may consider other variables such as information quality and personalization of content that have been recognized as facilitators for adherence (eg, [27]).

\section{Reasons for Abandoning the Use of Digital Self-Tracking Devices}

A 2015 study [28] suggested that one-third of consumer wearables end up in a drawer 6 months after purchase or initial use. We observed a slightly reduced observation of this phenomenon, with $25.54 \%$ of owners (259/1014) who had stopped using their connected devices at the time of the survey. When asked "Why did you stop using your device(s)?" a majority of respondents $(111 / 259,42.9 \%)$ said they had "lost interest after a while." Other reasons included malfunctioning of the device $(51 / 259,19.7 \%)$, doubts about the reliability of the data $(39 / 259 ; 15.1 \%)$, and "the device was acquired more out of curiosity" (38/259, 14.7\%). Most interestingly, we found that while abandoning use of these devices was not associated with gender, age, region, education, or main occupation, it was more prevalent among those who perceive there current health status as "poor or fair" compared with those who self-report their health status as good or excellent $\left(\chi^{2}=6.6 ; P=.048\right)$.

\section{Reasons for Not Owning Digital Self-Tracking Devices}

Respondents who do not own consumer health wearables or connected devices $(n=2035)$ were asked why. Our results indicate that $46.93 \%$ of this segment $(955 / 2035)$ did not see the interest in owning such tools. Other obstacles to greater diffusion of digital self-tracking devices were related to cost (836/2035, $41.08 \%$ ), lack of knowledge about the value or benefits associated with the use of these devices $(368 / 2035,18.08 \%)$, and doubts about the reliability of data $(341 / 2035,16.76 \%)$. As many nonowners have limited knowledge of the value proposition for such devices, it is not surprising to observe that intentions to buy and adopt one in the near future were relatively low. Indeed, slightly less than $15 \%$ of nonowners (14.99\%, $305 / 2035$ ) reported that they intend to acquire a health wearable or smart medical device in the next 12 months. 
Table 7. Users' appreciation of connected care technologies.

\begin{tabular}{|c|c|c|c|}
\hline Variable and items & $\begin{array}{l}\text { Somewhat or strongly } \\
\text { disagree, } \mathrm{n}(\%)\end{array}$ & Neutral, n (\%) & $\begin{array}{l}\text { Somewhat or strongly } \\
\text { agree, } \mathrm{n}(\%)\end{array}$ \\
\hline \multicolumn{4}{|l|}{ Perceived usefulness } \\
\hline I have maintained or improved my health condition & $31(5.4)$ & $151(26.1)$ & $398(68.5)$ \\
\hline I am more informed about my health & $47(8.1)$ & $147(25.1)$ & $387(66.6)$ \\
\hline My knowledge of my health condition has improved & $51(8.8)$ & $179(30.9)$ & $350(60.3)$ \\
\hline I feel more confident taking care of my health & $51(8.8)$ & $194(33.5)$ & $435(57.7)$ \\
\hline I am more autonomous in the management of my health & $37(6.4)$ & $215(37.1)$ & $328(56.5)$ \\
\hline I feel less anxious about my health & $81(14.1)$ & $239(41.2)$ & $259(44.8)$ \\
\hline I have more informed discussions with my doctor & $94(16.1)$ & 249 (42.9) & $238(41.0)$ \\
\hline \multicolumn{4}{|l|}{ User friendliness } \\
\hline I find it easy to use my wearables or smart devices & $18(3.1)$ & $57(9.8)$ & $506(87.1)$ \\
\hline I find my wearables or smart devices user-friendly & $22(3.9)$ & $58(9.9)$ & $500(86.2)$ \\
\hline Learning how to use my wearables or smart devices was easy & $28(4.9)$ & $65(11.3)$ & $486(83.9)$ \\
\hline $\begin{array}{l}\text { The information provided stored in the mobile apps is easy to understand and } \\
\text { interpret }\end{array}$ & $29(5.0)$ & $57(9.9)$ & $493(85.1)$ \\
\hline \multicolumn{4}{|l|}{ User satisfaction } \\
\hline I am satisfied with the use of my wearables or smart devices & $28(4.8)$ & $71(12.2)$ & $481(83.0)$ \\
\hline I am pleased with the use of my wearables or smart devices & $28(4.8)$ & $71(12.2)$ & $481(83.0)$ \\
\hline I am delighted with the use of my wearables or smart devices & $25(4.4)$ & $114(19.6)$ & $441(76.0)$ \\
\hline \multicolumn{4}{|l|}{ Confirmation of initial expectations } \\
\hline $\begin{array}{l}\text { My initial expectations concerning my use of wearables or smart devices } \\
\text { have been confirmed so far }\end{array}$ & $26(4.6)$ & $109(18.7)$ & $445(76.7)$ \\
\hline Using my wearables or smart devices turned out to be easier that I first thought & $36(6.2)$ & $141(24.3)$ & $404(69.5)$ \\
\hline $\begin{array}{l}\text { There are more benefits to using my wearables or smart devices than I first } \\
\text { thought }\end{array}$ & $42(7.3)$ & $150(25.8)$ & $388(66.8)$ \\
\hline \multicolumn{4}{|l|}{ Intention to continue using } \\
\hline $\begin{array}{l}\text { I have every intention of continuing to use wearables or smart devices in the } \\
\text { future }\end{array}$ & $23(4.0)$ & $45(7.8)$ & $511(88.2)$ \\
\hline $\begin{array}{l}\text { I will continue to use wearables or smart devices to monitor different aspects } \\
\text { of my health }\end{array}$ & $19(3.2)$ & $70(12.0)$ & $492(84.7)$ \\
\hline $\begin{array}{l}\text { I have no intention of stopping my use of wearables or smart devices in the } \\
\text { future }\end{array}$ & $22(3.9)$ & $64(11.1)$ & $493(85.1)$ \\
\hline
\end{tabular}

Table 8. Descriptive statistics and variance shared by the variables ( $\mathrm{N}=580)$. The ratios in italics on the diagonal represent the square root of the variance shared by each variable and its respective items. The ratios above the diagonal are Pearson correlation coefficients between variables.

\begin{tabular}{|c|c|c|c|c|c|c|c|c|}
\hline Variables & $\begin{array}{l}\text { Mean (SD); } \\
1-5\end{array}$ & $\begin{array}{l}\text { Number } \\
\text { of items }\end{array}$ & $\begin{array}{l}\text { Cronbach } \\
\text { alpha }\end{array}$ & $\begin{array}{l}\text { Perceived } \\
\text { usefulness }\end{array}$ & $\begin{array}{l}\text { Ease of } \\
\text { use }\end{array}$ & $\begin{array}{l}\text { Confirmation } \\
\text { of initial ex- } \\
\text { pectations }\end{array}$ & User satisfaction & $\begin{array}{l}\text { Intention to } \\
\text { continue } \\
\text { usage }\end{array}$ \\
\hline Perceived usefulness & $3.6(0.7)$ & 7 & .90 & .80 & $.53^{\mathrm{a}}$ & $.77^{\mathrm{a}}$ & $.66^{\mathrm{a}}$ & $.56^{\mathrm{a}}$ \\
\hline Ease of use & $4.2(0.7)$ & 4 & .92 & - & .90 & $.71^{\mathrm{a}}$ & $.73^{\mathrm{a}}$ & $.74^{\mathrm{a}}$ \\
\hline Confirmation of initial expectations & $3.9(0.7)$ & 3 & .80 & - & - & .84 & $.77^{\mathrm{a}}$ & $.67^{\mathrm{a}}$ \\
\hline User satisfaction & $4.1(0.8)$ & 3 & .89 & - & - & - & .90 & $.70^{\mathrm{a}}$ \\
\hline Intention to continue usage & $4.3(0.8)$ & 3 & .91 & - & - & - & - & .92 \\
\hline
\end{tabular}

${ }^{\mathrm{a}} P<.001$ 
Figure 1. Users' appreciation of smart devices $(\mathrm{N}=580)$; *** $\mathrm{P}<.005 ; * * \mathrm{P}<.01 ; * \mathrm{P}<.05$.

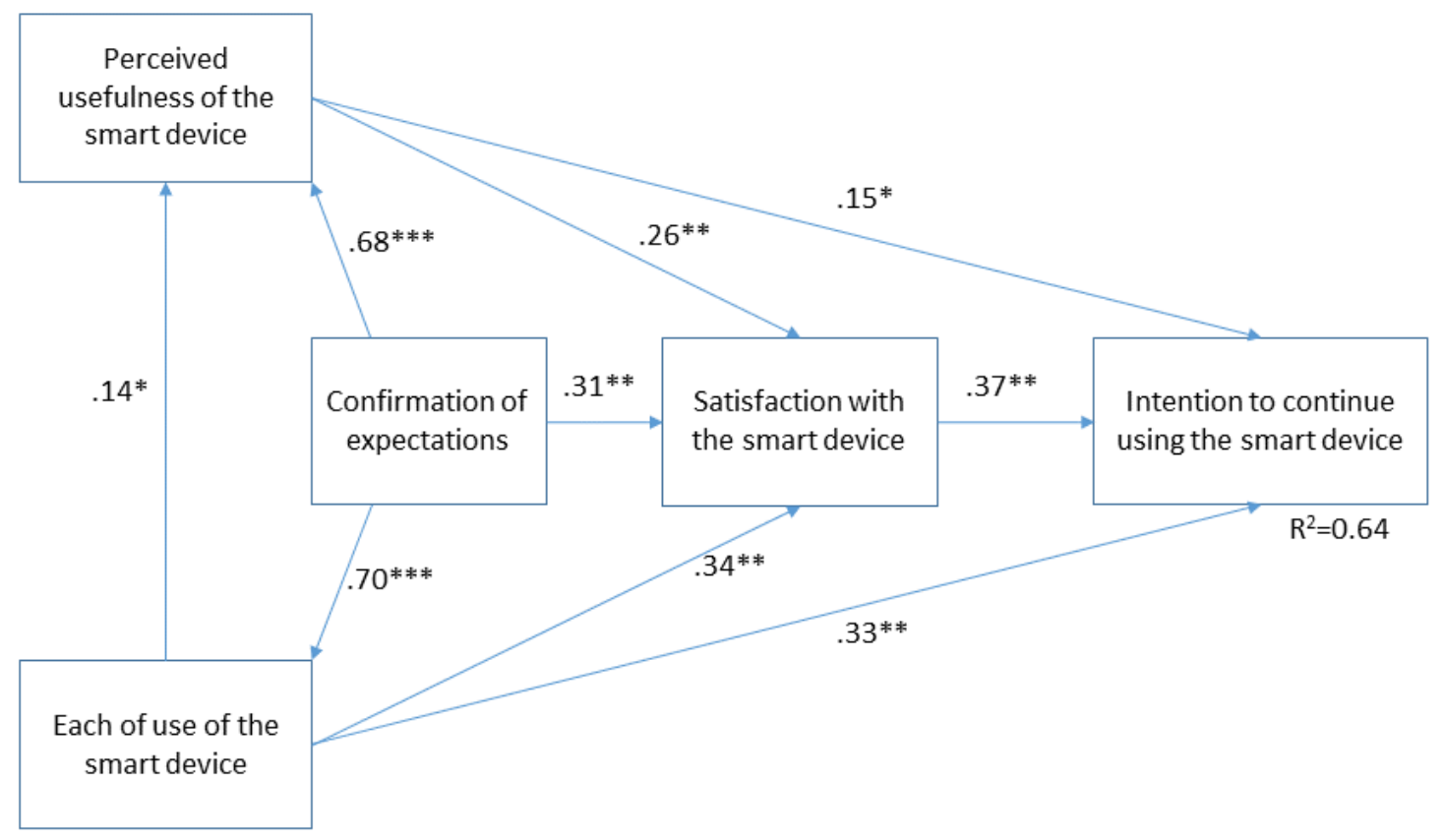

\section{Discussion}

\section{Strengths and Limitations}

This study investigates Canadian adults' digital health self-tracking behaviors and their use of connected wearables and devices to monitor aspects of their health and well-being. To our knowledge, it is one of the most comprehensive studies on this topic, resulting in highly reliable estimates of findings. Hence, our results set important baseline information that will guide future research on the evolution of the quantified-self phenomenon. Importantly, these findings are relevant to the information and technology industry and mHealth app developers to better understand the current market, segments, and viabilities to achieve behavioral and clinical outcomes. We further contributed to the extant literature by investigating novel, yet important aspects and issues, including the reasons for self-tracking and nontracking, the barriers to adoption of digital devices, consumers' appreciation of wearables and smart devices, the perceived benefits associated with digital self-tracking, and the reasons for usage discontinuance. Hence, this work may inform future policies and efforts in relation to general incorporation of self-tracking digital devices as supportive tools for patient care or reimbursement for technology-enabled quality outcome models of care.

Notwithstanding these strengths and contributions, our results must be interpreted with caution because of some inherent limitations. First, the responses relied on self-report and included only people who participate in Web panels managed by the survey company. Second, this is a cross-sectional survey, and while helpful for examining self-tracking behaviors and use of connected care technologies at one point in time, it is likely that people vary their use patterns and behaviors over time. Third, we did not collect data about race and ethnicity, although these variables might be related to the use of connected health technologies. Finally, our survey did not include people's health literacy, which may represent an important moderator.

\section{Implications for Practice and Research}

Our survey first reveals that the digital health self-tracking movement in Canada is still in an early stage. About one in 4 respondents currently owns a health wearable or smart medical device. Among them, 57.20\% (580/1014) use their smart devices on a regular basis for self-tracking purposes. Digital health self-trackers are mainly young, highly educated, and wealthy individuals whose main motivation for use of connected technologies is to monitory or quantify their fitness behaviors or progress on fitness goals. These results indicate an important presence of a significantly health engaged and activated segment of the Canadian population. Indeed, our findings show that many Canadian adults self-track aspects of their health because of the ubiquitous nature of mobile apps for health and consumer wearables and connected devices.

Although the use of connected care technologies could potentially benefit the growing population of patients with chronic conditions $[29,30]$, the question remains as to whether it will diffuse broadly beyond early adopters and across cost inequities. Although technology manufacturers may assume patients with chronic conditions have unlimited enthusiasm for tracking their own health data using self-tracking devices, reality seems to be otherwise. Indeed, our findings show that $29.3 \%$ of those with chronic conditions in our sample had abandoned the use of their devices at some point compared with $13.8 \%$ for those with no chronic diseases $(P=.04)$. A plausible explanation may be that chronic patients often consider it work (ie, a consuming and tiring task) to track their own health data [31]. This would suggest that digital self-tracking devices will successfully spread among chronic patients only if they are highly activated as patients and use is not experienced as a burden on the user but a positive and rewarding user experience. 
The use of gamification and positive reinforcement techniques $[32,33]$ may represent effective ways of making the experience more enjoyable and useful for chronic patients. Another explanation may be associated with the fact that medical parameters being tracked by chronic patients can be emotionally charged [31]. Indeed, "bad" data values can be extremely upsetting for many patients, especially when they are perceived to have some link to behavior. A third explanation may be that HCPs, especially physicians, do not seem interested in patients' self-logged data-even data that may be entirely objectively logged [31]. We believe chronic patients, especially those with severe conditions, may need personal coaching and continued support from HCPs to ensure adherence, system continuance, and positive health outcomes. This recommendation is also aligned with the importance of properly managing users' expectations discussed earlier.

To deepen our understanding of usage discontinuance, a prevalent phenomenon identified in these results, we suggest that future research include an approach that borrows a model proposed by Li et al [7]. This model outlines five psychological stages in the process of engaging in digital self-tracking. The first stage, called preparation, concerns people's motivation to collect personal information, how they determine what information to collect, and how they will record it. The next step, collection, is when people collect information about themselves. Integration is the stage where the information collected is prepared, combined, or transformed for the use to reflect on (reflection stage). Finally, action is when people choose what they are going to do with their newfound understanding of themselves (eg, people may tailor their behaviors to match their goals). A key finding of Li et al's study is that individuals have a tendency to focus on a single stage (ie, collecting data on number of steps or hours slept) and to ignore the overall process and intended outcome of self-tracking for health outcomes. This reinforces the importance of providing professional coaching and continued support. Among others, future studies could use this model to identify the barriers that people, especially chronic patients, experience when they self-track using connected care technologies.

Although $70 \%$ of digital self-trackers in our sample feel they have maintained or improved their health by using wearables and smart devices, there is little empirical evidence that suggest self-tracking personal health indicators leads to long-term behavioral changes [34]. Among the few studies we found, one trial concludes that the use of pedometers along with nursing consultations increased physical activity among older adults [35]. In another trial, the use of a wearable tracker by overweight and obese adults led to a small increase in moderate-to-vigorous intensity physical activity at follow-up [36]. More research with large samples is definitely needed to determine the effectiveness of wearable connected devices on people's physical activity. It is also unclear whether such devices can motivate adults of all age groups toward other important health mediating behaviors such as adopting a healthy diet, maintaining a healthy weight, adopting good sleep habits, and not smoking. Because healthy behaviors will lead to significant improvements in population health only if they are sustained [37], it will also be important that future (longitudinal) trials investigate whether and under which conditions (eg, health literacy) digital health self-tracking devices can support the creation and maintenance of enduring new lifestyle habits and improve quality of life.

Finally, prior research shows that connected care technologies may create new opportunities for individuals who desire to participate actively in and take responsibility for their personal health. As discussed in Kitsiou et al [38], mobile apps along with consumer wearables and smart medical devices can provide a platform for home telemonitoring programs for chronic patients. Furthermore, physicians can use wearable sensors to monitor acute patients' health in real time, which can aid with diagnosis and treatment decisions [34]. For instance, chronic sleep apnea can be diagnosed with a lightweight wearable that measures heart rate, breathing volume, and snoring instead of a heavy polysomnography assessment [39]. In addition, incorporating wearable and smart device sensors into routine care may improve clinician-patient relationships and increase patient empowerment [40]. It also appears that the widespread integration of these devices into medical practice by clinicians is extremely limited [41]. A recent survey of 989 Canadian HCPs shows that only $30 \%$ recommend wearable trackers (eg, smartwatch and bracelet) to their patients, and $25 \%$ recommend medical smart devices such as blood pressure monitors and sleep trackers [42]. Several barriers related to patient safety, data accuracy and security, reimbursement policy, and government regulation have been discussed in the extant literature (eg, [29,43]). Future research must continue investigating these important issues for practicing clinicians so that we develop a better understanding of how and under which circumstances the use of connected care technologies can best serve medicine, in general, and prevention and management of chronic conditions, in particular.

\section{Acknowledgments}

The authors would like to thank Mirou Jaana, Spyros Kitsiou, Marie-Pascale Pomey, and four anonymous reviewers for their helpful comments and suggestions on earlier versions of this manuscript. Canada Health Infoway is also acknowledged for providing financial support for this research. Last, we are indebted to Miguel Renato Aguirre for his assistance during the survey development phase.

\section{Conflicts of Interest}

None declared. 


\section{Multimedia Appendix 1}

Survey instrument.

[PDF File (Adobe PDF File), 213KB-Multimedia Appendix 1]

\section{References}

1. Topol E. The Patient Will See You Now: The Future of Medicine Is in Your Hands. New York, NY: Basic Books; 2015.

2. PwC Health Research Institute. PWC. Health wearables: early days URL: https://www.pwc.com/us/en/health-industries/ health-research-institute/publications/health-wearables-early-days.html [accessed 2017-10-26] [WebCite Cache ID $\underline{6 \mathrm{uViK} 9 \mathrm{t} 3 \mathrm{e}]}$

3. Gartner. 2017. Gartner says 8 billion connected things will be in use in 2017, up 31 percent from 2016 URL: https://www. gartner.com/newsroom/ [accessed 2017-10-27] [WebCite Cache ID 6uWhuGgxF]

4. Soreon Research. 2014. The wearable health revolution URL: http://www.soreonresearch.com/ wearable-healthcare-report-2014/ [accessed 2017-10-27] [WebCite Cache ID 6uWfIU59C]

5. Hoy MB. Personal activity trackers and the quantified self. Med Ref Serv Q 2016;35(1):94-100. [doi: 10.1080/02763869.2016.1117300] [Medline: 26794199]

6. Lupton D. The Quantified Self: A Sociology of Self-Tracking. United Kingdom: Cambridge: Polity Press; 2016.

7. Li I, Dey A, Forlizzi J. A stage-based model of personal informatics systems. 2010 Presented at: SIGCHI Conference on Human Factors in Computing Systems; April 10-15, 2010; Atlanta, GA.

8. Altschuler A, Picchi T, Nelson M, Rogers JD, Hart J, Sternfeld B. Physical activity questionnaire comprehension: lessons from cognitive interviews. Med Sci Sports Exerc 2009 Feb;41(2):336-343 [FREE Full text] [doi: 10.1249/MSS.0b013e318186b1b1] [Medline: 19127192]

9. Archer E, Pavela G, Lavie CJ. The inadmissibility of what we eat in America and NHANES dietary data in nutrition and obesity research and the scientific formulation of national dietary guidelines. Mayo Clin Proc 2015 Jul;90(7):911-926 [FREE Full text] [doi: 10.1016/j.mayocp.2015.04.009] [Medline: 26071068]

10. van Gemert-Pijnen JE, Nijland N, van Limburg M, Ossebaard HC, Kelders SM, Eysenbach G, et al. A holistic framework to improve the uptake and impact of eHealth technologies. J Med Internet Res 2011;13(4):e111 [FREE Full text] [doi: 10.2196/jmir.1672] [Medline: 22155738]

11. Kelders SM, Kok RN, Ossebaard HC, Van Gemert-Pijnen JE. Persuasive system design does matter: a systematic review of adherence to web-based interventions. J Med Internet Res 2012;14(6):e152 [FREE Full text] [doi: 10.2196/jmir.2104] [Medline: 23151820]

12. Fox S. Pew Research Center. Washington, DC: Pew Research Center; 2013. The self-tracking data explosion URL: $\underline{\text { http:/ }}$ /www.pewinternet.org/2013/06/04/the-self-tracking-data-explosion/,[WebCite Cache ID 6ibYNkRt6]

13. Accenture Consulting. Accenture. 2016. Patients want a heavy dose of digital URL: https://www.accenture.com/us-en/ insight-research-shows-patients-united-states-want-heavy [accessed 2017-10-26] [WebCite Cache ID 6uVitf2ZA]

14. Brown B. Health Tech Insider. 2016 Aug 25. Salesforce's 2016 connected patient report: insights into patient preferences on telemedicine, wearables and post-discharge care, 2016 URL: http://healthtechinsider.com/2016/08/25/ 2016-connected-patient-report/[WebCite Cache ID 6uWiWu7XF]

15. IFOP. 2015. Objets connectes et usage des donnees: la perception des Francais URL: http://www.ifop.fr/media/poll/ 3250-1-study file.pdf [accessed 2017-10-27] [WebCite Cache ID 6uWiqaOSm]

16. Global GfK. GFK. 2016. Health and fitness tracking URL: http://www.gfk.com/global-studies/global-studies-fitness-tracking/ [accessed 2017-10-26] [WebCite Cache ID 6uVjHS2UI]

17. Eysenbach G. Improving the quality of Web surveys: the Checklist for Reporting Results of Internet E-Surveys (CHERRIES). J Med Internet Res 2004 Sep 29;6(3):e34 [FREE Full text] [doi: 10.2196/jmir.6.3.e34] [Medline: 15471760]

18. Bowling A. Just one question: If one question works, why ask several? J Epidemiol Community Health 2005 May;59(5):342-345 [FREE Full text] [doi: 10.1136/jech.2004.021204] [Medline: 15831678]

19. Davis FD. Perceived usefulness, perceived ease of use, and user acceptance of information technology. MIS Q 1989;13(3):319-340.

20. Bhattacherjee A. Understanding information systems continuance: an expectation-confirmation model. MIS Quarterly 2001;25(3):351-370 [FREE Full text]

21. Hong S, Thong JY, Tam KY. Understanding continued information technology usage behaviour: a comparison of three models in the context of mobile internet. Decis Support Syst 2006;42(3):1819-1834. [doi: 10.1016/j.dss.2006.03.009]

22. Canadian Radio-Television and Telecommunications Commission. Crtc.gc. 2016. Communication monitoring report URL: http://crtc.gc.ca/eng/publications/reports/PolicyMonitoring/2016/cmri.htm[WebCite Cache ID 6uWj1GsJK]

23. Fox S, Duggan M. Pewinternet. Washington, DC: Pew Internet \& American Life; 2013. Health Online URL: http://www. pewinternet.org/Reports/2013/Health-online/Summary-of-Findings.aspx [accessed 2013-11-20] [WebCite Cache ID 6LH0VgIUW]

24. Canada Health Infoway. 2016. Connecting patients for better health URL: https://www.infoway-inforoute.ca/en/component/ edocman/resources/3152-connecting-patients-for-better-health-2016 [accessed 2018-01-27] [WebCite Cache ID 6uVjOPO5P] 
25. Oliver RL. A cognitive model of the antecedents and consequences of satisfaction decisions. J Mark Res 1980:460-469 [FREE Full text]

26. Nunnally J. Psychometric Methods. New York, NY: McGraw-Hill; 1978.

27. Zhao J, Freeman B, Li M. Can mobile phone apps influence people's health behaviour change? An evidence review. J Med Internet Res 2016 Oct 31;18(11):e287 [FREE Full text] [doi: 10.2196/jmir.5692] [Medline: 27806926]

28. Ledger D, McCaffrey D. Blog.endeavour.partners. Cambridge, MA: Endeavour Partners; 2014. Inside wearables: How the science of human behaviour change offers the secret to long-term engagement, Endeavour Partners: Cambridge, MA URL: https://blog.endeavour.partners/ inside-wearable-how-the-science-of-human-behavior-change-offers-the-secret-to-long-term-engagement-a15b3c7d4cf3?gi=b08cfb919c55 [accessed 2018-04-26] [WebCite Cache ID 6yy9e5sj4]

29. Piwek L, Ellis DA, Andrews S, Joinson A. The rise of consumer health wearables: promises and barriers. PLoS Med 2016 Feb;13(2):e1001953 [FREE Full text] [doi: 10.1371/journal.pmed.1001953] [Medline: 26836780]

30. Kitsiou S, Paré G, Jaana M. Effects of home telemonitoring interventions on patients with chronic heart failure: an overview of systematic reviews. J Med Internet Res 2015;17(3):e63 [FREE Full text] [doi: 10.2196/jmir.4174] [Medline: 25768664]

31. Ancker JS, Witteman HO, Hafeez B, Provencher T, Van de Graaf M, Wei E. You get reminded you're a sick person: personal data tracking and patients with multiple chronic conditions. J Med Internet Res 2015;17(8):e202 [FREE Full text] [doi: 10.2196/jmir.4209] [Medline: 26290186]

32. Leahey T, Rosen J. DietBet: a web-based program that uses social gaming and financial incentives to promote weight loss. JMIR Serious Games 2014 Feb 07;2(1):e2 [FREE Full text] [doi: 10.2196/games.2987] [Medline: 25658966]

33. Miller AS, Cafazzo JA, Seto E. A game plan: gamification design principles in mHealth applications for chronic disease management. Health Informatics J 2014 Jul 1;22(2):184-193. [doi: 10.1177/1460458214537511] [Medline: 24986104]

34. Wu Q, Sum K, Nathan-Roberts D. How fitness trackers facilitate health behaviour change. In: Proceedings of the Human Factors and Ergonomics Society Annual Meeting.: SAGE Publications; 2016 Presented at: Human Factors and Ergonomics Society Annual Meeting; 2016; Los Angeles, CA URL: http://journals.sagepub.com/doi/pdf/10.1177/1541931213601247

35. Harris T, Kerry SM, Victor CR, Ekelund U, Woodcock A, Iliffe S, et al. A primary care nurse-delivered walking intervention in older adults: PACE (pedometer accelerometer consultation evaluation)-Lift cluster randomised controlled trial. PLoS Med 2015 Feb;12(2):e1001783 [FREE Full text] [doi: 10.1371/journal.pmed.1001783] [Medline: 25689364]

36. Wang JB, Cadmus-Bertram LA, Natarajan L, White MM, Madanat H, Nichols JF, et al. Wearable sensor/device (Fitbit One) and SMS text-messaging prompts to increase physical activity in overweight and obese adults: a randomized controlled trial. Telemed J E Health 2015 Oct;21(10):782-792. [doi: 10.1089/tmj.2014.0176] [Medline: 26431257]

37. Patel MS, Asch DA, Volpp KG. Wearable devices as facilitators, not drivers, of health behavior change. J Am Med Assoc 2015 Feb 3;313(5):459-460. [doi: 10.1001/jama.2014.14781] [Medline: 25569175]

38. Kitsiou S, Paré G, Jaana M, Gerber B. Effectiveness of mHealth interventions for patients with diabetes: an overview of systematic reviews. PLoS One 2017;12(3):e0173160 [FREE Full text] [doi: 10.1371/journal.pone.0173160] [Medline: 28249025]

39. Harrington J, Schramm PJ, Davies CR, Lee-Chiong TL. An electrocardiogram-based analysis evaluating sleep quality in patients with obstructive sleep apnea. Sleep Breath 2013 Sep;17(3):1071-1078. [doi: 10.1007/s11325-013-0804-9] [Medline: 23354509]

40. Appelboom G, Camacho E, Abraham ME, Bruce SS, Dumont EL, Zacharia BE, et al. Smart wearable body sensors for patient self-assessment and monitoring. Arch Public Health 2014;72(1):28 [FREE Full text] [doi: 10.1186/2049-3258-72-28] [Medline: 25232478]

41. Canada Health Infoway. 2017. Use of Electronic Medical Records among Canadian Physicians URL: https://www. infoway-inforoute.ca/en/what-we-do/news-events/newsroom/2016-news-releases/ 6752-canadian-physicians-can-improve-patient-care-with-advanced-emr-use [accessed 2017-11-10] [WebCite Cache ID 6us0nF2kj]

42. Canada Health Infoway. 2017. Canadians and Digital Health URL: https://www.infoway-inforoute.ca/en/component/ edocman/resources/reports/2815-infographic-report-on-digital-health-canadians-embracing-digital-health[WebCite Cache ID 6ecgdxQQt]

43. West DM. How mobile devices are transforming healthcare issues in technology innovation. Issues Technol Innov 2012;18:14 [FREE Full text]

\section{Abbreviations}

HCP: health care provider

mHealth: mobile health

PLS: partial least squares

TAM: Technology Acceptance Model 
Edited by $N$ Cahill, $S$ Hagens, $G$ Eysenbach; submitted 10.11.17; peer-reviewed by H Witteman, S Berrouiguet, B Price, $S$ Choemprayong; comments to author 16.12.17; revised version received 30.01.18; accepted 31.03.18; published 02.05.18

Please cite as:

Paré G, Leaver C, Bourget C

Diffusion of the Digital Health Self-Tracking Movement in Canada: Results of a National Survey

J Med Internet Res 2018;20(5):e177

URL: http://www.jmir.org/2018/5/e177/

doi: 10.2196/jmir.9388

PMID: 29720359

(C) Guy Paré, Chad Leaver, Claire Bourget. Originally published in the Journal of Medical Internet Research (http://www.jmir.org), 02.05.2018. This is an open-access article distributed under the terms of the Creative Commons Attribution License (https://creativecommons.org/licenses/by/4.0/), which permits unrestricted use, distribution, and reproduction in any medium, provided the original work, first published in the Journal of Medical Internet Research, is properly cited. The complete bibliographic information, a link to the original publication on http://www.jmir.org/, as well as this copyright and license information must be included. 